\title{
Nitrato em alface e mobilidade do íon em solo adubado com composto de lixo urbano
}

\author{
José Ricardo Mantovani(1), Manoel Evaristo Ferreira( ${ }^{(1)}$ e Mara Cristina Pessôa da Cruz ${ }^{(1)}$
}

(1)Universidade Estadual Paulista, Fac. de Ciências Agrárias e Veterinárias, Dep. de Solos e Adubos, Via de Acesso Prof. Paulo Donato Castellane s/no, CEP 14884-900 Jaboticabal, SP. E-mail: mantovanijr@yahoo.com, evaristo@fcav.unesp.br, mcpcruz@fcav.unesp.br

\begin{abstract}
Resumo - A contaminação do meio ambiente por nitrato pelo uso agrícola do composto de lixo urbano tem sido pouco estudada. O objetivo deste trabalho foi avaliar o efeito da adubação com composto de lixo urbano no acúmulo de nitrato em alface, na mobilidade no solo e nas perdas por lixiviação de nitrato. Dois experimentos simultâneos foram realizados em casa de vegetação, em colunas de PVC, em delineamento em blocos ao acaso, com cinco tratamentos e quatro repetições. Em um deles efetuou-se um cultivo de alface e, no outro, dois cultivos sucessivos. Os tratamentos constituíram-se de cinco doses de composto de lixo urbano, equivalentes a 0, 30, 60, 90 e $120 \mathrm{t} \mathrm{ha}^{-1}$. As colunas receberam solo das profundidades de 0-20 (tratado com composto de lixo), 20-40 e 40-60 cm de um Argissolo, textura média, e uma muda de alface. O composto de lixo urbano não torna a alface imprópria para o consumo no que diz respeito à concentração de nitrato, mas apresenta potencial de contaminação de lençol freático causado pelas perdas do íon por lixiviação.
\end{abstract}

Termos para indexação: Lactuca sativa, nitrogênio, lixiviação.

\section{Nitrate in lettuce and ion mobility in soil fertilized with urban waste compost}

\begin{abstract}
Environmental contamination by nitrate due to the agricultural use of urban waste compost has been poorly studied. The objective of this work was to evaluate the effect of urban waste compost on nitrate accumulation in lettuce, on nitrate mobility in soil and on nitrate losses by leaching, in two successive cultivations. Two simultaneous experiments were carried out in greenhouse, in PVC columns, in randomized blocks design, with five treatments and four replicates. In one of them a lettuce cultivation was carried out and in the other one, two sucessive cultivations. The treatments were five urban waste compost rates, equivalents to $0,30,60,90$ and $120 \mathrm{t} \mathrm{ha}^{-1}$. Columns were filled with soil from depths of 0-20 (treated with waste compost), 20-40 and 40-60 cm of a medium texture Ultisol, and one lettuce seedling. Urban waste compost does not turn the lettuce inappropriate to be consumed due to the nitrate concentration but it is of potential risk to the contamination of the groundwater due to nitrate leaching.
\end{abstract}

Index terms: Lactuca sativa, nitrogen, leaching.

\section{Introdução}

O composto de lixo urbano é um adubo orgânico que promove melhorias nas características químicas, físicas e biológicas do solo (Giusquiani et al., 1995). Assim como a maioria dos adubos orgânicos, é fonte importante de $\mathrm{N}$, mas, dependendo da concentração, das doses de composto e da freqüência de aplicação, há risco ao ambiente em virtude da lixiviação de nitrato e, conseqüentemente, contaminação das águas subterrâneas.

A lixiviação de nitrato é influenciada pela textura, quantidade de adubo aplicado, tipo de adubação, exigência e absorção de $\mathrm{N}$ pelas plantas, quantidade e freqüência de precipitação pluvial, manejo da irrigação, condições de drenagem e dinâmica das transformações do N como mineralização, imobilização e desnitrificação (Campbell et al., 1993).

Dynia (2000) constatou que o nitrato apresenta mobilidade acentuada em solos tropicais, com acúmulo do íon entre 220 e $460 \mathrm{~cm}$ de profundidade, em solo argiloso, e entre 340 e $600 \mathrm{~cm}$ de profundidade, em solo arenoso, portanto muito abaixo da zona de exploração radicular da maioria das culturas. Perdas de nitrato por lixiviação também foram verificadas em experimentos com composto de lixo, lodo de esgoto ou esterco bovino (Chang \& Entz, 1996; Mamo et al., 1999; Anjos \& Mattiazzo, 2000; Oliveira et al., 2001a; 2001b). 
A contaminação das águas subterrâneas com nitrato é preocupante, pois são a principal fonte de água potável de inúmeros municípios brasileiros (Alaburda \& Nishihara, 1998). Segundo Muchovej \& Rechcigl (1995), águas com concentração de $\mathrm{N}$ nítrico $\left(\mathrm{N}_{-} \mathrm{NO}_{3}{ }^{-}\right)$acima de $3 \mathrm{mg} \mathrm{L}^{-1}$ são consideradas contaminadas. Entretanto, a Organização Mundial de Saúde (OMS) estabeleceu, quanto à água potável, concentração máxima acei-

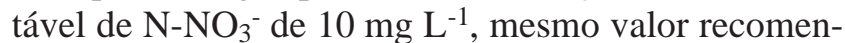
dado pelas legislações americana e brasileira (Alaburda \& Nishihara, 1998).

A ingestão do íon nitrato pelo homem por meio da água ou de alimentos resulta na formação de nitrosaminas, que são carcinogênicos, e em metemoglobinemia em crianças, doença em que ocorre o impedimento do transporte de oxigênio dos alvéolos pulmonares para os tecidos, o que pode acarretar morte (Greenwood \& Hunt, 1986).

Entre os alimentos que mais acumulam nitrato estão as hortaliças folhosas, como a alface, em cujo cultivo é recomendado uso simultâneo de estercos e adubos industriais como fonte de $\mathrm{N}$ e outros nutrientes (Trani et al., 1997). O composto de lixo urbano pode ser um dos substitutos para os estercos e é utilizado há mais de 20 anos nos cinturões verdes do Estado de São Paulo, em doses anuais de 40 a $60 \mathrm{t} \mathrm{ha}^{-1}$. Nessas áreas, os problemas com a lixiviação de nitrato são agravados pelo cultivo durante o ano todo, pela localização em áreas de baixadas, próximas a cursos d'água e, conseqüentemente, com lençol freático pouco profundo, e pela irrigação (Oliveira et al., 2001b).

O objetivo deste trabalho foi avaliar o efeito da adubação com composto de lixo urbano no acúmulo de nitrato em alface, na mobilidade no solo e nas perdas por lixiviação de nitrato, em dois cultivos sucessivos.

\section{Material e Métodos}

Dois experimentos simultâneos foram realizados em casa de vegetação, em colunas de PVC, no período de setembro de 2001 a janeiro de 2002. Em um deles foi feito um cultivo de alface (experimento 1) e, no outro, dois cultivos sucessivos (experimento 2). Foram utiliza- das amostras de um Argissolo Vermelho-Amarelo distrófico, coletadas em área de pastagem, nas profundidades de 0-20, 20-40 e 40-60 cm. A caracterização química de rotina (P, MO, $\mathrm{pH}, \mathrm{K}, \mathrm{Ca}, \mathrm{Mg}, \mathrm{H}+\mathrm{Al}, \mathrm{CTC}$ e

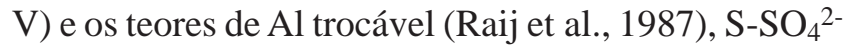
(Cantarella \& Prochnow, 2001), B (Abreu et al., 1994) e Zn (Abreu et al., 2001) encontram-se na Tabela 1.

Na análise granulométrica (Camargo et al., 1986), foram obtidos, em $\mathrm{g} \mathrm{kg}^{-1}$, 160 de argila, 770 de areia e 70 de silte, na profundidade de $0-20 \mathrm{~cm} ; 280$ de argila, 680 de areia e 40 de silte, na profundidade de $20-40 \mathrm{~cm}$ e, 330 de argila, 620 de areia e 50 de silte, na profundidade de $40-60 \mathrm{~cm}$.

Em cada experimento, empregou-se delineamento em blocos ao acaso, com cinco tratamentos e quatro repetições. Os tratamentos constituíram-se de cinco doses de composto de lixo urbano, equivalentes a 0, 30, 60, 90 e $120 \mathrm{t} \mathrm{ha}^{-1}$. O adubo orgânico foi analisado segundo Kiehl (1985) e apresentou $60 \mathrm{~g} \mathrm{~kg}^{-1}$ de umidade, $\mathrm{pH}$ em $\mathrm{CaCl}_{2}, 7,4$ e, na base seca: C, $157 \mathrm{~g} \mathrm{~kg}^{-1}, \mathrm{~N}, 14 \mathrm{~g} \mathrm{~kg}^{-1}$, relação C/N, 11/1; P, K, Ca e Mg, respectivamente, iguais a 4, 2, 25 e $4 \mathrm{~g} \mathrm{~kg}^{-1}$; Cu, Fe, Mn e Zn, respectivamente, iguais a 181, 26.852, 412 e $544 \mathrm{mg} \mathrm{kg}^{-1}$.

Porções de $6,78 \mathrm{dm}^{3}$ de solo da camada superficial $(0-20 \mathrm{~cm})$, correspondentes a $8,35 \mathrm{~kg}$, receberam $\mathrm{CaCO}_{3}$ p.a. e $4 \mathrm{MgCO}_{3} \cdot \mathrm{Mg}(\mathrm{OH})_{2} \cdot 5 \mathrm{H}_{2} \mathrm{O}$ p.a., na proporção Ca:Mg de 3:1, para elevar V a 70\%, e o composto de lixo, de acordo com cada tratamento. A seguir, as porções de solo tratadas com os insumos foram transferidas para vasos de plástico de $8 \mathrm{~L}$, umedecidas com água deionizada a $60 \%$ da capacidade de retenção, e permaneceram incubadas por 33 dias. Aos 23 dias de incubação foi feita adubação mineral conforme Mantovani et al. (2003) e todos os vasos receberam na forma de solução (mg vaso-1 ${ }^{-1}$ : 550 de P, 962 de K, 110 de $S$ e 2,75 de $B$. Ao final da incubação, uma amostra de $0,5 \mathrm{dm}^{3}$ de solo de cada vaso foi coletada para análises químicas.

As colunas de PVC foram compostas por três anéis de $20 \mathrm{~cm}$ de diâmetro, unidos por fita adesiva, e um “cap" (tampão) acoplado ao anel inferior. Cada anel possuía $20 \mathrm{~cm}$ de altura, exceto o superior, que tinha $2 \mathrm{~cm}$ a mais para facilitar as irrigações. As paredes internas dos

Tabela 1. Caracterização química do solo utilizado no experimento.

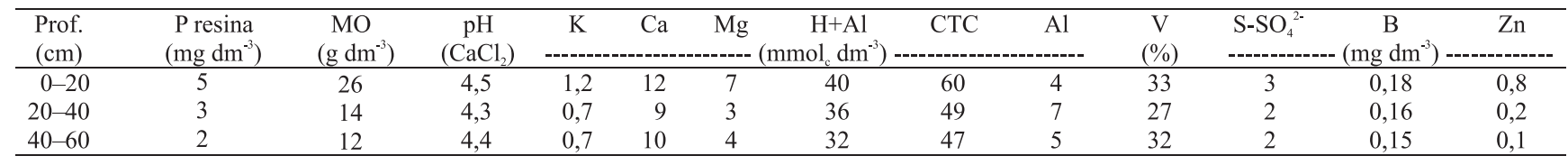


anéis de PVC receberam uma camada de resina líquida, sobre a qual foi espalhada uma mistura de areia grossa (diâmetro acima de 1,5 mm) e areia fina (diâmetro de 1,5 a 0,5 mm), previamente lavadas, na proporção de 2:1 (v:v), com a finalidade de criar rugosidade e evitar o escoamento preferencial de água pelas paredes da coluna. Para coleta de lixiviado, foi feito, próximo a base de cada “cap”, um orifício lateral de $1 \mathrm{~cm}$ de diâmetro, e nele foi introduzida uma mangueira de plástico de $14 \mathrm{~cm}$ de comprimento, de tal maneira que cerca de $4 \mathrm{~cm}$ da mesma ficavam do lado de fora do "cap". Para facilitar a drenagem, o fundo de cada "cap” de PVC foi preenchido com esferas de isopor de $15 \mathrm{~mm}$ de diâmetro mais $0,5 \mathrm{dm}^{3}$ de areia fina lavada.

As colunas de PVC foram colocadas em suportes de ferro para facilitar as pesagens feitas para controle de umidade, e foram preenchidas com auxílio de funil com haste longa, com $6,28 \mathrm{dm}^{3}$ de solo de cada profundidade, totalizando $18,84 \mathrm{dm}^{3}$ de solo por coluna, de modo que o solo da camada de 40-60 cm ocupou o anel inferior; o de 20-40 cm, o intermediário, e o de $0-20 \mathrm{~cm}$ (tratado com carbonatos, composto de lixo e adubos), o anel superior. Em seguida, o solo de cada coluna foi umedecido a $60 \%$ da capacidade de retenção de água e recebeu, em 23/10/2001, uma muda de alface do grupo crespa, cultivar Verônica. A adubação nitrogenada foi feita por meio de solução de uréia (p.a.), de modo a aplicar parceladamente $480 \mathrm{mg}$ de N por coluna: $20 \%$ no transplantio e $30 \%, 20 \%$ e $30 \%$, respectivamente, aos 10, 20 e 30 dias após o transplantio. Aos 32 dias após o transplantio, aplicaram-se 375 mg de K por coluna, por meio de solução.

Aos 24 (primeira coleta) e aos 34 dias após o transplantio (segunda coleta), com o solo na umidade adequada (60\% da capacidade de retenção), adicionaram-se em cada coluna de uma só vez, $500 \mathrm{~mL}$ de água deionizada a cada 30 min até completar $3 \mathrm{~L}$, o que eqüivale a uma lâmina total de $96 \mathrm{~mm}$, para elevar o teor de água do solo acima de $100 \%$ da capacidade de retenção e propiciar cerca de $500 \mathrm{~mL}$ de lixiviado por coluna. Os lixiviados foram coletados em recipientes de plástico, e o volume foi medido com proveta. Em alíquotas de $5 \mathrm{~mL}$ de lixiviado, foi feita a determinação de $\mathrm{N}$ amoniacal $\left(\mathrm{N}-\mathrm{NH}_{4}{ }^{+}\right)$e $\mathrm{N}-\mathrm{NO}_{3}{ }^{-}$por meio de destilação em microdestilador Kjeldahl e subseqüente titulação do destilado (Bremner \& Keeney, 1965).

A colheita das plantas foi iniciada 38 dias após o transplantio. Foram colhidas duas repetições por dia, das 6 h30 às 7h30, pois, de acordo com Maynard et al. (1976), a intensidade luminosa e a temperatura influenciam o acúmulo de nitrato em plantas. As plantas foram cortadas rente à superfície do solo, pesadas e, rapidamente, colocadas em sacos de plástico e mantidas em geladeira a $4^{\circ} \mathrm{C}$, até serem lavadas e secadas conforme Bataglia et al. (1983).

A matéria seca obtida foi moída em moinho do tipo Wiley, e subamostras foram trituradas em almofariz para passar em peneira de $0,355 \mathrm{~mm}$ (42 mesh) de abertura de malha. Na matéria seca das plantas, foi feita determinação de $\mathrm{N}$ orgânico $+\mathrm{N}^{-} \mathrm{NH}_{4}{ }^{+}(\mathrm{NOA})$, por meio de digestão sulfúrica, destilação dos extratos em microdestilador Kjeldahl e subseqüente titulação do destilado (Sarruge \& Haag, 1974), e de nitrato, por meio de extração do íon com água deionizada, passagem dos extratos em coluna de cádmio esponjoso para redução do nitrato a nitrito, e quantificação colorimétrica do nitrito (Follett \& Ratcliff, 1963).

Após a colheita das plantas, as colunas do experimento 1 foram desmontadas para coleta de amostra de solo de cada anel, as quais foram conservadas em freezer, conforme recomendação de Mattos Junior et al. (1995), para posterior determinação de $\mathrm{N}$ inorgânico $\left(\mathrm{N}-\mathrm{NH}_{4}{ }^{+}\right.$e $\left.\mathrm{N}-\mathrm{NO}_{3}{ }^{-}\right)$, segundo Bremner \& Keeney (1965). A umidade das amostras foi determinada e os resultados expressos em peso de solo seco.

No experimento 2, desenvolveu-se o segundo cultivo de alface. Para tanto, o solo de cada coluna foi reumedecido a $60 \%$ da capacidade de retenção de água e recebeu, em 10/12/2001, uma muda da cultivar Verônica. A adubação nitrogenada foi idêntica à do primeiro cultivo, e a adubação potássica de cobertura (750 mg de K por coluna) foi feita por meio de solução e parcelada aos 10 e aos 30 dias após o transplantio. As demais etapas, lixiviações, colheita das plantas, coleta das amostras de solo, análises de solo, planta e lixiviado, foram feitas conforme descrito para o primeiro cultivo.

Os resultados referentes a nitrato no solo e no lixiviado foram expressos como $\mathrm{N}-\mathrm{NO}_{3}{ }^{-}$e na planta como $\mathrm{NO}_{3}{ }^{-}$. Os resultados foram submetidos à análise de variância, teste de comparação de médias (Tukey a $5 \%$ de probabilidade) e regressão polinomial. Na análise estatística dos resultados de $\mathrm{N}-\mathrm{NH}_{4}{ }^{+}$e $\mathrm{N}-\mathrm{NO}_{3}{ }^{-}$no solo, foi empregada análise de variância em parcelas subdivididas, com as doses de composto de lixo como tratamentos principais e as profundidades como subtratamentos. Nas demais análises estatísticas, foram utilizadas análises de variância em delineamento em blo- 
cos ao acaso. Quanto aos teores e quantidades acumuladas de $\mathrm{NOA}$ e de $\mathrm{NO}_{3}{ }^{-}$na matéria seca das plantas do primeiro cultivo, foram utilizados os resultados dos dois experimentos, ou seja, oito repetições, e no segundo cultivo, foram usados os resultados do experimento 2, portanto quatro repetições.

\section{Resultados e Discussão}

O composto de lixo urbano não afetou os teores de $\mathrm{N}$ orgânico $+\mathrm{N}^{-\mathrm{NH}_{4}}{ }^{+}(\mathrm{NOA})$ na parte aérea das plantas, nos dois cultivos, e os teores médios no primeiro e no segundo cultivos foram 21,7 e $24,1 \mathrm{~g} \mathrm{~kg}^{-1}$, respectivamente. Esses teores de NOA ficaram abaixo dos considerados adequados para alface, 30 a $50 \mathrm{~g} \mathrm{~kg}^{-1}$ (Trani \& Raij, 1997) e $37,5 \mathrm{~g} \mathrm{~kg}^{-1}$ (Fontes et al., 1997). As diferenças entre os valores obtidos e os mencionados pelos autores podem ser atribuídas à parte e à idade da planta consideradas por Trani \& Raij (1997), folhas de alface recém-desenvolvidas coletadas na metade do ciclo, e à cultivar empregada por Fontes et al. (1997), Brasil 202, que foram diferentes das utilizadas neste experimento. Além disso, não foram observados sintomas de deficiência de $\mathrm{N}$ nas plantas na fase experimental.

No primeiro cultivo, houve aumento linear das quantidades acumuladas de NOA na parte aérea das plantas, em razão das doses de composto de lixo. No segundo cultivo, o efeito foi quadrático, sendo constatado aumento até a dose de $80 \mathrm{t} \mathrm{ha}^{-1}$ do adubo orgânico, estimada pelo modelo matemático (Figura 1). O comportamento di-

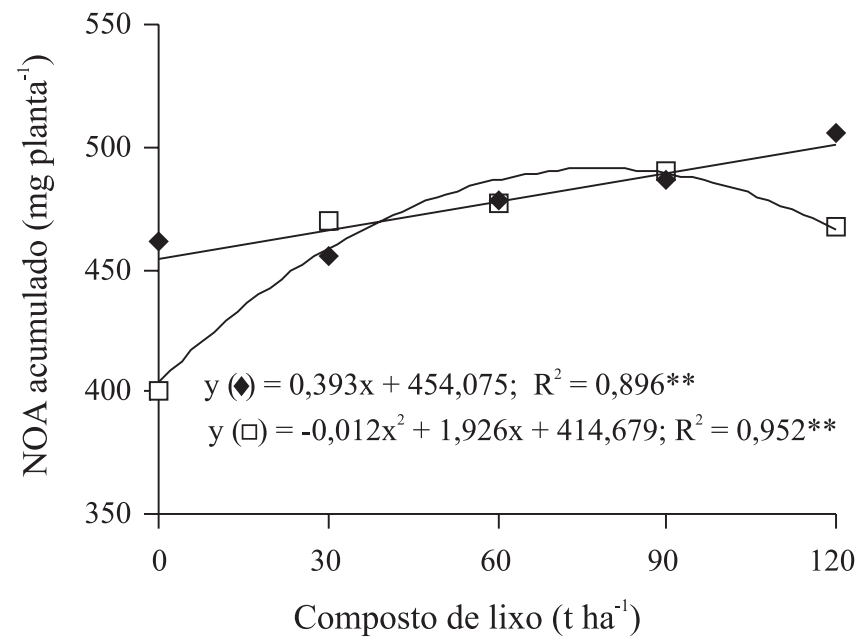

Figura 1. Quantidades acumuladas de $\mathrm{N}$ orgânico $+\mathrm{N}-\mathrm{NH}_{4}{ }^{+}$ (NOA) na parte aérea de alface, no primeiro ( ) e no segundo cultivo $(\square)$, em razão da adubação com composto de lixo

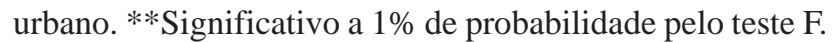

ferenciado no acúmulo de NOA entre os cultivos pode ser atribuído à menor disponibilidade de $\mathrm{N}$ no segundo cultivo decorrente da maior extração no primeiro cultivo, que, aliada às perdas por lixiviação, proporcionaram empobrecimento do solo.

Os teores de $\mathrm{NO}_{3}{ }^{-}$na matéria seca da parte aérea das plantas variaram de 5,36 a $6,44 \mathrm{~g} \mathrm{~kg}^{-1}$ no primeiro cultivo de alface, e de 4,21 a $7,40 \mathrm{~g} \mathrm{~kg}^{-1}$ no segundo cultivo, em razão da adubação com composto de lixo urbano. Na conversão dos teores de $\mathrm{NO}_{3}{ }^{-}$na matéria seca para matéria fresca, obtém-se a seguinte variação: 0,47 a $0,86 \mathrm{~g} \mathrm{~kg}^{-1}$ no primeiro cultivo e 0,31 a $0,52 \mathrm{~g} \mathrm{~kg}^{-1}$ no segundo. Esses valores ficaram abaixo do limite máximo tolerável de $\mathrm{NO}_{3}{ }^{-}$estabelecido pela Comunidade Européia, que é de 2,50 e de $3,50 \mathrm{~g} \mathrm{~kg}^{-1}$ de matéria fresca para alface cultivada em condições de campo e em ambiente protegido, respectivamente (McCall \& Willumsen, 1998). No primeiro cultivo, as quantidades acumuladas de $\mathrm{NO}_{3}{ }^{-}$na parte aérea das plantas aumentaram a partir da dose estimada de $54 \mathrm{t} \mathrm{ha}^{-1}$ de composto de lixo e, no segundo, o aumento foi linear com a aplicação do adubo orgânico (Figura 2). No primeiro cultivo, as diferenças entre os tratamentos nas quantidades acumuladas de $\mathrm{NO}_{3}{ }^{-}$na parte aérea das plantas foram menores do que $10 \%$ e o maior acúmulo nas plantas do tratamento-testemunha em relação às que receberam doses intermediárias de composto de lixo pode ser atribuído ao fato de que o acúmulo do íon em plantas é influenciado não só pela disponibili-

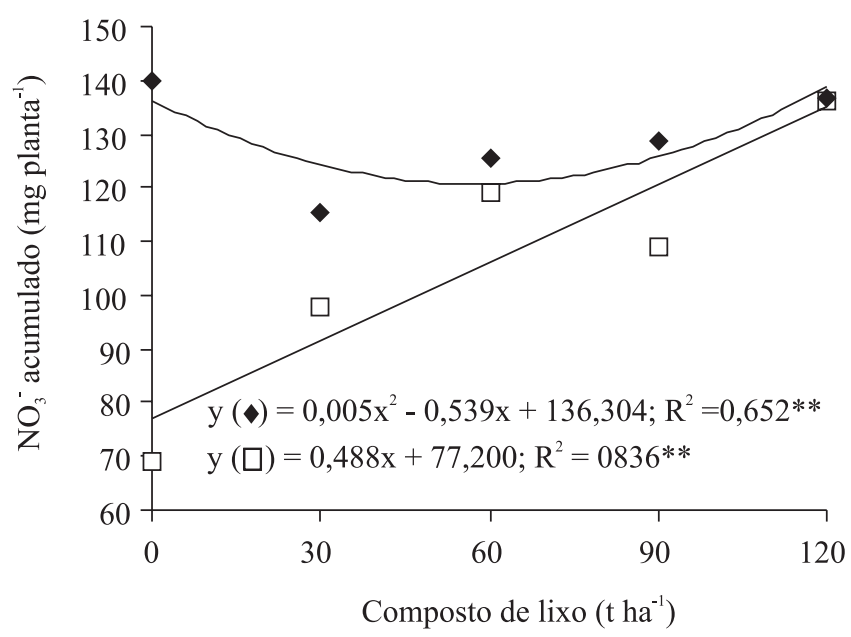

Figura 2. Quantidades acumuladas de $\mathrm{NO}_{3}{ }^{-}$na parte aérea de alface, no primeiro $(\bullet)$ e no segundo cultivo ( $\square$ ), em razão da adubação com composto de lixo urbano. **Significativo a 1\% de probabilidade pelo teste $\mathrm{F}$. 
dade de nitrogênio, mas também por outros fatores como temperatura e intensidade luminosa (Maynard et al., 1976). Foi constatado efeito residual do composto de lixo nas quantidades acumuladas de $\mathrm{NOA}$ e de $\mathrm{NO}_{3}{ }^{-}$na parte aérea de alface.

Não foi observado efeito do composto de lixo nos teores de $\mathrm{N}-\mathrm{NH}_{4}{ }^{+}$no solo ao final do primeiro e do segundo cultivo de alface. Por sua vez, houve variação significativa dos teores do íon entre as profundidades, e os teores médios foram de 1,1, 10,5 e 11,6 $\mathrm{mg} \mathrm{kg}^{-1}$ nas profundidades de $0-20$, 20-40 e 40-60 cm, respectivamente, ao final do primeiro cultivo, e de 2,4, 1,2 e $10,8 \mathrm{mg} \mathrm{kg}^{-1}$, após o segundo. Portanto, no solo, a maior

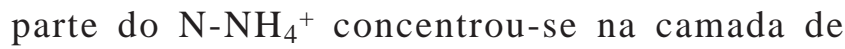
$40-60 \mathrm{~cm}$. Os baixos teores de $\mathrm{N}-\mathrm{NH}_{4}{ }^{+}$no solo aliados ao alto coeficiente de variação dos resultados (CV>30\%) podem explicar as diferenças entre os cultivos em relação aos teores do íon na camada de 20-40 cm.

Quanto ao $\mathrm{N}-\mathrm{NO}_{3}{ }^{-}$, verificou-se, ao final do primeiro cultivo, nas profundidades de $0-20$ e de $20-40 \mathrm{~cm}$, que os teores foram baixos (menores que $5 \mathrm{mg} \mathrm{kg}^{-1}$ ) e não variaram com a aplicação de composto de lixo, ao passo que, na camada de 40-60 cm, os teores aumentaram com a aplicação do adubo orgânico até a dose estimada de $107 \mathrm{t} \mathrm{ha}^{-1}$ e variaram de 19 a $39 \mathrm{mg} \mathrm{kg}^{-1}$ (Figura 3). Também foram constatadas diferenças significativas nos teores de $\mathrm{N}^{-\mathrm{NO}_{3}}{ }^{-}$na profundidade de $40-60 \mathrm{~cm}$ em relação às demais $(0-20$ e 20-40 cm), e em todos os

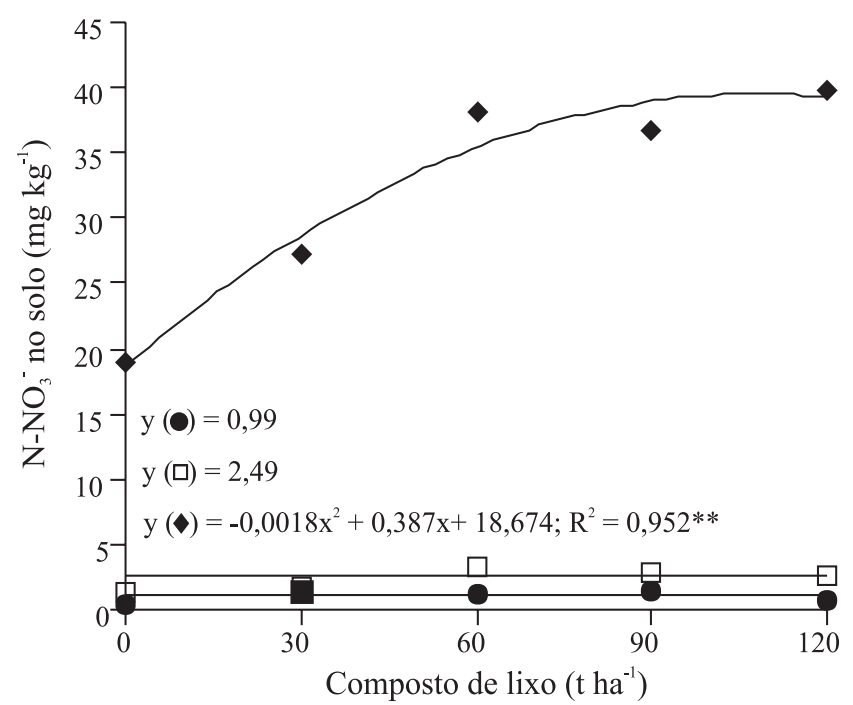

Figura 3. Teores de $\mathrm{N}^{-} \mathrm{NO}_{3}{ }^{-}$no solo das colunas após o primeiro cultivo de alface, em razão da adubação com composto de lixo urbano nas profundidade de 0-20 cm (๑), 20-40 cm ( $\square)$ e 40-60 cm( ( ). **Significativo a 1\% de probabilidade pelo teste F. tratamentos, cerca de $90 \%$ do $\mathrm{N}^{-\mathrm{NO}_{3}}{ }^{-}$se concentrou na profundidade de $40-60 \mathrm{~cm}$, o que indica alta mobilidade do íon no solo. Após o segundo cultivo não foi observado efeito do composto de lixo urbano nos teores de $\mathrm{N}^{-} \mathrm{NO}_{3}{ }^{-}$no solo, em razão das perdas por lixiviação. Contudo, os teores do íon aumentaram com a profundidade, e em média, $87 \%$ do $\mathrm{N}-\mathrm{NO}_{3}{ }^{-}$se concentrou na camada de 40-60 cm (Figura 4), e dificilmente seria absorvido pelas plantas por estar fora do alcance das raízes, pois verificou-se, por ocasião da separação dos anéis das colunas, que o sistema radicular da alface se restringiu aos $20 \mathrm{~cm}$ superficiais.

Chang \& Entz (1996), Oliveira et al. (2001a, 2001b), utilizando, respectivamente, esterco bovino, lodo de esgoto e composto de lixo urbano, também verificaram

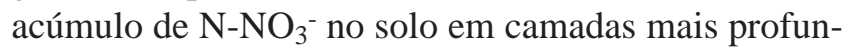
das. Em contrapartida, Eriksen et al. (1999) e Wolkowski (2003) não observaram aumento nos teores de $\mathrm{N}^{-\mathrm{NO}_{3}}{ }^{-}$ em profundidade com a aplicação de composto de lixo. O composto de lixo utilizado nesses casos possuía relação C/N alta (40/1 no primeiro caso, 37/1 e 35/1 no segundo), e a planta-teste empregada foi o milho, que tem sistema radicular muito mais profundo que a alface.

Como esperado, os teores de $\mathrm{N}-\mathrm{NO}_{3}-$ do solo ao final de cada cultivo foram muito maiores do que os de $\mathrm{N}-\mathrm{NH}_{4}{ }^{+}$, com a diferença de $125 \%$, em média. O predomínio da forma nítrica em relação à amoniacal em solos bem drenados ocorre por causa da rápida oxi-

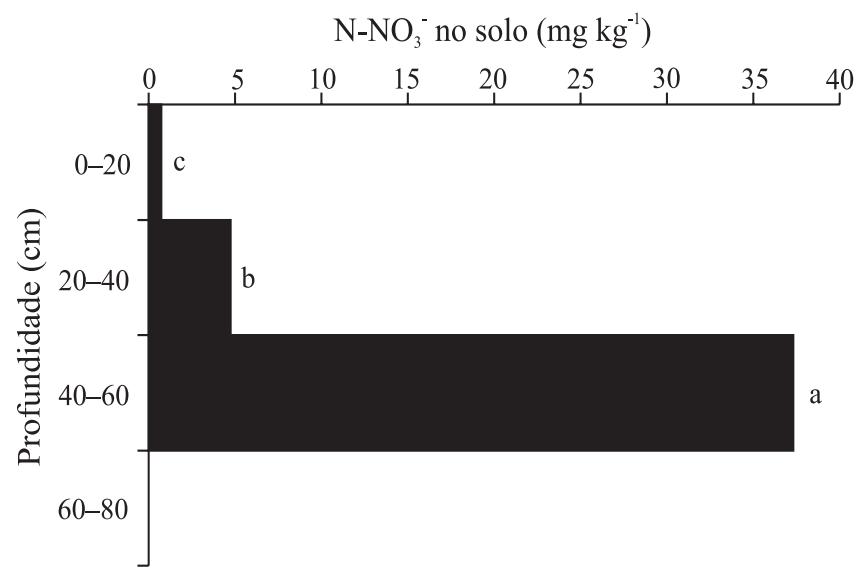

Figura 4. Teores de $\mathrm{N}-\mathrm{NO}_{3}{ }^{-}$no solo das colunas após o segundo cultivo de alface, em razão da profundidade. As letras indicam diferenças significativas nos teores de $\mathrm{N}-\mathrm{NO}_{3}{ }^{-}$entre profundidades, pelo teste de Tukey, a 5\% de probabilidade. 
dação do amônio a nitrato por microrganismos autotróficos (Victoria et al., 1992).

O volume de lixiviado coletado nas colunas em que se conduziram um e dois cultivos de alface, com exceção da primeira coleta, foi significativamente maior no tratamento-testemunha do que no que recebeu a maior dose de composto de lixo urbano, ou seja, $120 \mathrm{t} \mathrm{ha}^{-1}$ (Tabela 2). Essa diferença deve ter ocorrido em virtude do aumento da capacidade de retenção de água no solo com a aplicação do adubo orgânico (Giusquiani et al., 1995).

Os teores e as quantidades de $\mathrm{N}-\mathrm{NH}_{4}{ }^{+}$no lixiviado das colunas que receberam um e dois cultivos de alface não foram afetados significativamente nem apresentaram tendência definida com a adubação com composto de lixo (Tabela 3). Além disso, das quantidades totais de $\mathrm{N}$-inorgânico lixiviadas em cada cultivo, cerca de 8\% estavam na forma amoniacal e o restante na forma nítrica. Resultados similares foram obtidos por Anjos \& Mattiazzo (2000) e Oliveira et al. (2001a) com a aplicação de lodo de esgoto, e por Oliveira et al. (2001b) com composto de lixo. Esses autores verificaram que mais de $97 \%$ do $\mathrm{N}$ perdido por lixiviação estava na forma de $\mathrm{N}-\mathrm{NO}_{3}{ }^{-}$.

Os teores de $\mathrm{N}^{-} \mathrm{NO}_{3}{ }^{-}$no lixiviado das colunas que receberam um e dois cultivos de alface aumentaram linearmente com a aplicação de composto de lixo, sendo que, nas que receberam um cultivo, a variação foi de 34 a 98 e de 97 a $245 \mathrm{mg} \mathrm{L}^{-1}$ na primeira e na segunda coletas, respectivamente, e nas que receberam dois cul-

Tabela 2. Volumes de lixiviado nas colunas que receberam um e dois cultivos de alface, em razão da adubação com composto de lixo urbano, na primeira, segunda, terceira e quarta coletas. Médias de quatro repetições.

\begin{tabular}{|c|c|c|c|c|c|c|}
\hline \multirow{3}{*}{$\begin{array}{l}\text { Composto de } \\
\text { lixo }\left(\mathrm{t} \mathrm{ha}^{-1}\right)\end{array}$} & \multicolumn{6}{|c|}{ Volume de lixiviado (mL) } \\
\hline & \multicolumn{2}{|c|}{ Um cultivo } & \multicolumn{4}{|c|}{ Dois cultivos } \\
\hline & Primeira & Segunda & Primeira & Segunda & Terceira & Quarta \\
\hline 0 & 458 & 598 & 495 & 595 & 900 & 771 \\
\hline 30 & 425 & 393 & 585 & 495 & 655 & 610 \\
\hline 60 & 478 & 390 & 483 & 393 & 565 & 553 \\
\hline 90 & 513 & 560 & 443 & 453 & 583 & 543 \\
\hline 120 & 475 & 370 & 433 & 335 & 625 & 563 \\
\hline Teste F & $0,36^{\mathrm{ns}}$ & $4,34 *$ & $1,91^{\mathrm{ns}}$ & $4,17^{*}$ & $7,88^{* *}$ & $3,56^{*}$ \\
\hline DMS & 238 & 224 & 197 & 220 & 217 & 227 \\
\hline CV $(\%)$ & 22 & 21 & 18 & 21 & 14 & 17 \\
\hline
\end{tabular}

nsNão-significativo. * e **Significativo a $5 \%$ e a $1 \%$ de probabilidade, respectivamente. tivos, a variação foi de 32 a 107, de 90 a 243, de 102 a 211 e de 96 a $174 \mathrm{mg} \mathrm{L}^{-1}$ na primeira, segunda, terceira e quarta coletas, respectivamente.

As quantidades lixiviadas de $\mathrm{N}-\mathrm{NO}_{3}{ }^{-}$aumentaram em cada coleta e na soma destas, em razão do aumento da dose de composto de lixo, o que evidencia o potencial poluente desse adubo orgânico em relação à contaminação de lençol freático com nitrato (Figura 5). Na comparação do tratamento-testemunha com o que recebeu a maior dose do adubo orgânico, verificou-se aumento de $115 \%$ e de $63 \%$ nas quantidades totais de $\mathrm{N}^{-\mathrm{NO}_{3}}{ }^{-}$lixiviadas nas colunas que receberam um e dois cultivos de alface, respectivamente. Com a aplicação de $60 \mathrm{tha}^{-1}$ de composto de lixo, dose normalmente utilizada, o aumento em relação à testemunha foi de 58\% e de 31\%, respectivamente.

Iglesias-Jimenes \& Alvarez (1993) constataram que doses elevadas de composto de lixo urbano (acima de $50 \mathrm{t} \mathrm{ha}^{-1}$ ) poderiam causar contaminação de águas subterrâneas com nitrato. Mamo et al. (1999) verificaram, ao longo de três anos, aumento nas perdas de $\mathrm{N}^{-\mathrm{NO}_{3}}{ }^{-}$ por lixiviação, até $1,2 \mathrm{~m}$ de profundidade, com a aplicação de composto de lixo urbano. Segundo os autores, as perdas com a adição de $270 \mathrm{t} \mathrm{ha}^{-1}$ do adubo orgânico, de uma só vez, foram cerca de $80 \%$ maiores do que com o seu parcelamento em aplicações anuais de $90 \mathrm{t} \mathrm{ha}^{-1}$ por três anos consecutivos. Oliveira et al. (2001b) observaram, em solo de textura média cultivado com cana-de-açúcar, aumento nas perdas de $\mathrm{N}_{-} \mathrm{NO}_{3}{ }^{-}$ por lixiviação com a aplicação de composto de lixo.

Tabela 3. Quantidades de $\mathrm{N}-\mathrm{NH}_{4}{ }^{+}$no lixiviado das colunas que receberam um e dois cultivos de alface, em razão da adubação com composto de lixo urbano, na primeira, segunda, terceira e quarta coletas e no total das coletas. Médias de quatro repetições.

\begin{tabular}{|c|c|c|c|c|c|c|c|c|}
\hline \multirow{3}{*}{$\begin{array}{l}\text { Composto de } \\
\text { lixo }\left(\mathrm{tha}^{-1}\right)\end{array}$} & \multicolumn{8}{|c|}{$\mathrm{N}^{-\mathrm{NH}_{4}}{ }^{+}\left(\mathrm{mg} \mathrm{coluna}^{-1}\right)$} \\
\hline & \multicolumn{3}{|c|}{ Um cultivo } & \multicolumn{5}{|c|}{ Dois cultivos } \\
\hline & $1^{\mathrm{a}}$ & $2^{\mathrm{a}}$ & Total & $1^{\mathrm{a}}$ & $2^{\mathrm{a}}$ & $3^{\mathrm{a}}$ & $4^{\mathrm{a}}$ & Total \\
\hline 0 & 4 & 9 & 13 & 3 & 8 & 10 & 7 & 28 \\
\hline 30 & 3 & 7 & 10 & 4 & 8 & 9 & 7 & 28 \\
\hline 60 & 4 & 7 & 11 & 2 & 4 & 10 & 8 & 24 \\
\hline 90 & 3 & 9 & 12 & 4 & 8 & 12 & 8 & 32 \\
\hline 120 & 4 & 8 & 12 & 4 & 6 & 12 & 9 & 31 \\
\hline Teste F & $1,0^{\text {ns }}$ & $1,1^{\mathrm{ns}}$ & $1,0^{\mathrm{ns}}$ & $3,9^{\text {ns }}$ & $1,9^{\text {ns }}$ & $0,7^{\mathrm{ns}}$ & $0,8^{\text {ns }}$ & $0,6^{\mathrm{ns}}$ \\
\hline DMS & 2 & 4 & 5 & 3 & 5 & 7 & 5 & 16 \\
\hline CV $(\%)$ & 27 & 23 & 20 & 42 & 37 & 28 & 29 & 26 \\
\hline
\end{tabular}

ns Não-significativo. 
Segundo esses autores, aplicações anuais do adubo orgânico acima de $24 \mathrm{t} \mathrm{ha} \mathrm{a}^{-1}$ oferecem risco de contaminação das águas subterrâneas com nitrato.
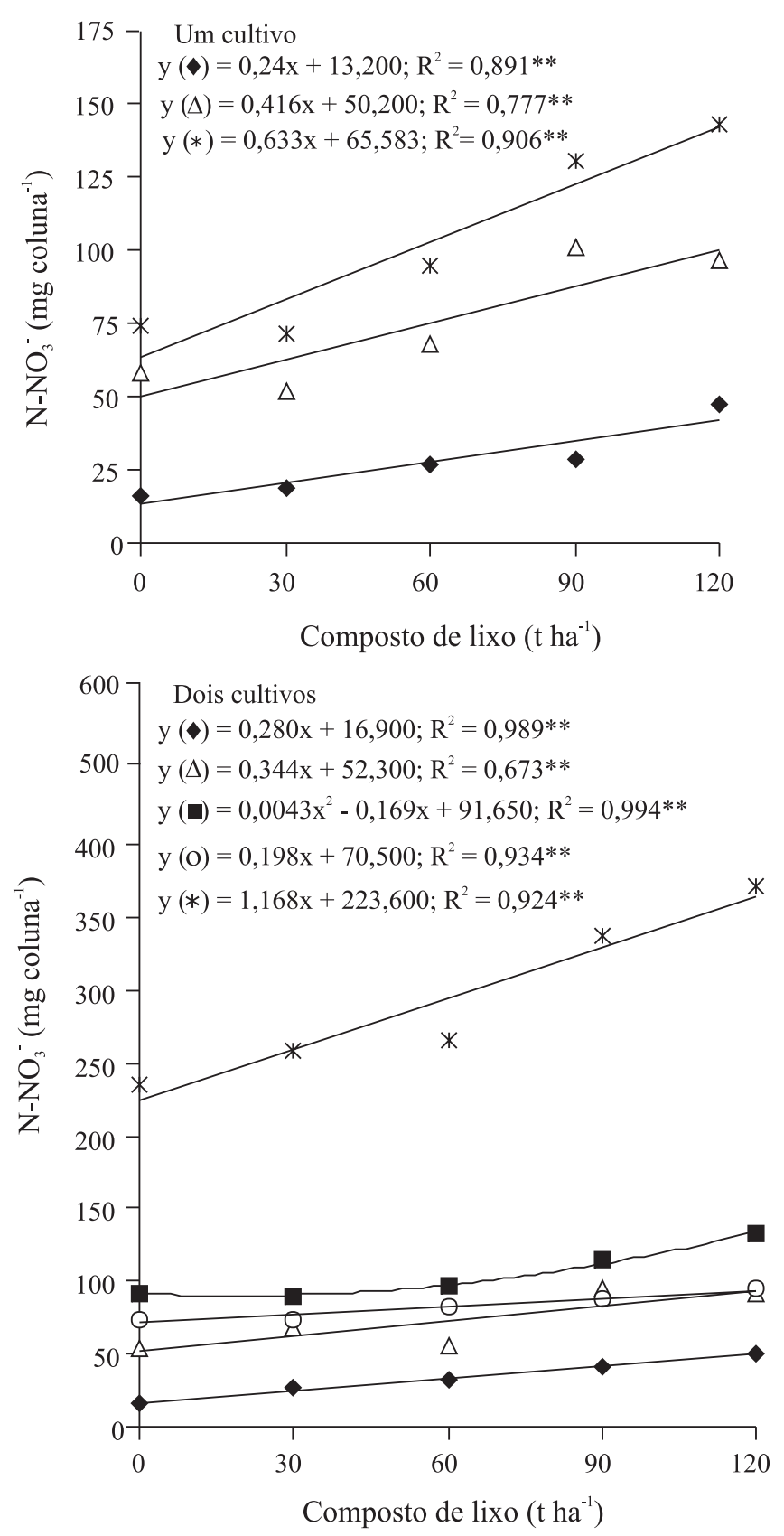

Figura 5. Quantidades de $\mathrm{N}-\mathrm{NO}_{3}{ }^{-}$no lixiviado das colunas que receberam um e dois cultivos de alface, em função da adubação com composto de lixo urbano, na primeira $(\diamond)$, segunda $(\triangle)$, terceira ( $(\mathbf{\square})$, quarta $(O)$ coletas e no total das coletas $(*)$.**Significativo a $1 \%$ de probabilidade pelo teste $\mathrm{F}$.

\section{Conclusões}

1. O composto de lixo urbano não torna a alface imprópria para o consumo em relação à concentração de nitrato.

2. Há risco potencial de contaminação de lençol freático causada pelas perdas do íon nitrato por lixiviação em áreas adubadas com composto de lixo urbano.

\section{Agradecimento}

À Fapesp, pela bolsa concedida a José Ricardo Mantovani.

\section{Referências}

ABREU, C.A.; ABREU, M.F.; ANDRADE, J.C. Determinação de cobre, ferro, manganês, zinco, cádmio, cromo, níquel e chumbo em solos usando a solução de DTPA em pH 7,3. In: RAIJ, B. van; ANDRADE, J.C.; CANTARELLA, H.; QUAGGIO, J.A. (Ed.). Análise química para avaliação da fertilidade de solos tropicais. Campinas: Instituto Agronômico, 2001. p.240-250.

ABREU, C.A.; ABREU, M.F.; RAIJ, B. van; BATAGLIA, O.C.; ANDRADE, J.C. Extraction of boron from soil by microwave heating for ICP-AES determination. Communications in Soil Science and Plant Analysis, v.25, p.3321-3333, 1994.

ALABURDA, J.; NISHIHARA, L. Presença de compostos de nitrogênio em águas de poços. Revista de Saúde Pública, v.32, p.160-165, 1998.

ANJOS, A.R.M.; MATTIAZZO, M.E. Lixiviação de íons inorgânicos em solos repetidamente tratados com biossólido. Revista Brasileira de Ciência do Solo, v.24, p.927-938, 2000.

BATAGLIA, O.C.; FURLANI, A.M.C.; TEIXEIRA, J.P.F.; FURLANI, P.R.; GALLO, J.R. Métodos de análise química de plantas. Campinas: Instituto Agronômico, 1983. 48p. (Boletim Técnico, 78).

BREMNER, J.M.; KEENEY, D.R. Exchangeable ammonium, nitrate and nitrite by steam-distillation methods. In: BLACK, C.A. (Ed.). Methods of soil analysis: chemical and microbiological properties. Madison: American Society of Agronomy; Soil Science Society of America, 1965. p.1191-1206.

CAMARGO, O.A.; MONIZ, A.C.; JORGE, J.A.; VALADARES, J.M.A.S. Métodos de análise química, mineralógica e física de solos do Instituto Agronômico de Campinas. Campinas: Instituto Agronômico, 1986. 94p. (Boletim Técnico, 106).

CAMPBELL, C.A.; ZENTNER, R.P.; SELLES, F.; AKINREMI, O.O. Nitrate leaching as influenced by fertilization in the Brown soil zone. Canadian Journal of Soil Science, v.73, p.387-397, 1993.

CANTARELLA, H.; PROCHNOW, L.I. Determinação de sulfato em solos. In: RAIJ, B. van; ANDRADE, J.C.; CANTARELLA, H.; QUAGGIO, J.A. (Ed.). Análise química para avaliação da fertilidade de solos tropicais. Campinas: Instituto Agronômico, 2001. p.225-230. 
CHANG, C.; ENTZ, T. Nitrate leaching losses under repeated cattle feedlot manure applications in Southern Alberta. Journal of Environmental Quality, v.25, p.145-153, 1996.

DYNIA, J.F. Nitrate retention and leaching in variable charge soils of watershed in São Paulo State, Brazil. Communications in Soil Science and Plant Analysis, v.31, p.777-791, 2000.

ERIKSEN, G.N.; COALE, F.J.; BOLLERO, G.A. Soil nitrogen dynamics and maize production in municipal solid waste amended soil. Agronomy Journal, v.91, p.1009-1016, 1999.

FOLLETT, M.J.; RATCLIFF, P.W. Determination of nitrite and nitrate in meat products. Journal of the Science of Food and Agriculture, v.14, p.138-144, 1963.

FONTES, P.C.R.; PEREIRA, P.R.G.; CONDE, R.M. Critical chlorophyll, total nitrogen, and nitrate-nitrogen in leaves associated to maximum lettuce yield. Journal of Plant Nutrition, v.20, p.10611068, 1997.

GIUSQUIANI, P.L.; PAGLIAI, M.; GIGLIOTTI, G.; BUSINELLI, D.; BENETTI, A. Urban waste compost: effects on physical, chemical and biochemical soil properties. Journal of Environmental Quality, v.24, p.175-182, 1995.

GREENWOOD, D.J.; HUNT, J. Effect of nitrogen fertiliser on the nitrate contents of field vegetables grown in Britain. Journal of the Science of Food and Agriculture, v.37, p.373-383, 1986.

IGLESIAS-JIMENEZ, E.; ALVAREZ, C.E. Apparent availability of nitrogen in composted municipal refuse. Biology and Fertility of Soils, v.16, p.313-318, 1993.

KIEHL, E.J. Fertilizantes orgânicos. São Paulo: Agronômica Ceres, 1985. 492p.

MAMO, M.; ROSEN, C.J.; HALBACH, T.R. Nitrogen availability and leaching from soil amended with municipal solid waste compost. Journal of Environmental Quality, v.28, p.1074-1082, 1999.

MANTOVANI, J.R.; FERREIRA, M.E.; CRUZ, M.C.P.; CHIBA, M.K.; BRAZ, L.T. Calagem e adubação com vermicomposto de lixo urbano na produção e nos teores de metais pesados em alface. Horticultura Brasileira, v.21, p.494-500, 2003.

MATTOS JUNIOR, D.; CANTARELLA, H.; RAIJ, B. van. Manuseio e conservação de amostras de solo para preservação do nitrogênio inorgânico. Revista Brasileira de Ciência do Solo, v.19, p.423-431, 1995.
MAYNARD, D.N.; BARKER, A.V.; MINOTTI, P.L.; PECK, N.H. Nitrate accumulation in vegetables. Advances in Agronomy, v.28, p.71-118, 1976.

McCALL, D.; WILLUMSEN, J. Effects of nitrate, ammonium and chloride application on the yield and nitrate content of soil-grown lettuce. Journal of Horticultural Science \& Biotechnology, v.73, p.698-703, 1998.

MUCHOVEJ, R.M.C.; RECHCIGL, J.E. Nitrogen fertilizers. In: RECHCIGL, J.E. (Ed.). Soil amendments and environmental quality. Boca Raton: Lewis Publishers, 1995. p.1-64.

OLIVEIRA, F.C.; MATTIAZZO, M.E.; MARCIANO, C.R.; MORAES, S.O. Lixiviação de nitrato em um Latossolo Amarelo distrófico tratado com lodo de esgoto e cultivado com cana-de-açúcar. Scientia Agricola, v.58, p.171-180, 2001a.

OLIVEIRA, F.C.; MATTIAZZO, M.E.; MARCIANO, C.R.; MORAES, S.O. Percolação de nitrato em Latossolo Amarelo distrófico afetada pela aplicação de composto de lixo urbano e adubação mineral. Revista Brasileira de Ciência do Solo, v.25, p.731-741, 2001b.

RAIJ, B. van; QUAGGIO, J.A.; CANTARELLA, H.; FERREIRA, M.E.; LOPES, A.S.; BATAGLIA, O.C. Análise química do solo para fins de fertilidade. Campinas: Fundação Cargill, 1987. 170p. SARRUGE, J.R.; HAAG, H.P. Análises químicas em plantas. Piracicaba: Esalq, 1974. 56p.

TRANI, P.E.; PASSOS, F.A.; AZEVEDO FILHO, J.A. Alface, almeirão, chicória, escarola, rúcula e agrião d’água. In: RAIJ, B. van; CANTARELLA, H.; QUAGGIO, J.A.; FURLANI, A.M.C.(Ed.). Recomendações de adubação e calagem para o Estado de São Paulo. 2.ed.rev.atual. Campinas: Instituto Agronômico/Fundação IAC, 1997. p.168-169. (Boletim Técnico, 100).

TRANI, P.E.; RAIJ, B. van. Hortaliças. In: RAIJ, B. van; CANTARELLA, H.; QUAGGIO, J.A.; FURLANI, A.M.C. (Ed.). Recomendações de adubação e calagem para o Estado de São Paulo. 2.ed.rev.atual. Campinas: Instituto Agronômico/Fundação IAC, 1997. p.157-164. (Boletim Técnico, 100).

VICTORIA, R.L.; PICCOLO, M.C.; VARGAS, A.A.T. O ciclo do nitrogênio. In: CARDOSO, E.J.B.N.; TSAI, S.M.; NEVES, M.C.P. (Ed.). Microbiologia do solo. Campinas: Sociedade Brasileira de Ciência do Solo, 1992. p.105-119.

WOLKOWSKI, R.P. Nitrogen management considerations for landspreading municipal solid waste compost. Journal of Environmental Quality, v.32, p.1844-1850, 2003. 